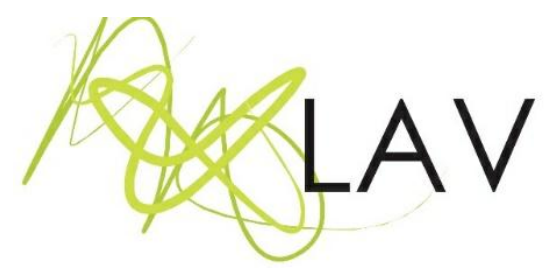

Blocos, infância e crianças: entre movimentos e ensaios brincantes

Blocks, childhood and children: between movements and playful essays

César Donizetti Leite

Universidade Estadual Paulista

\title{
Resumo
}

O propósito deste texto é apresentar-se como um jogo compositivo. Nele, estão expostos alguns elementos que se constituem como centrais na composição do texto-jogo. Estes elementos estão organizados em 6 faces e 5 fragmentos que objetivam se apresentarem como blocos. A proposta é criar um campo, em que o leitor-autor possa criar seus próprios movimentos. Sendo assim, o objetivo aqui é apresentar oportunidades de exercícios e espaços de produção de pensamentos, ideias, pensamentos, manifestações, imagens. Os elementos que constituem os fragmentos presentes no texto são a infância, a linguagem, a imagem, a arte e a criança.

Palavras-chave: Blocos de Sensações, Infância, Criança, Arte.

\begin{abstract}
The present article aims at being presented as a composite game. A number of elements approached constitute pillars to the text-game. These elements are organized in 6 faces and 5 fragments which aim at being be presented as blocks. The proposal is to create a field in which the reader-author is able to create their own movements. Therefore, the aim here is to present opportunities of exercises and spaces to produce thoughts, ideas, manifestations, images. The elements which constitute the fragments in the text are childhood, language, image, art and child.
\end{abstract}

Keywords: Blocks of sensations, Childhood, Child, Art. 


\section{Blocos, infância e crianças: entre movimentos e ensaios brincantes}

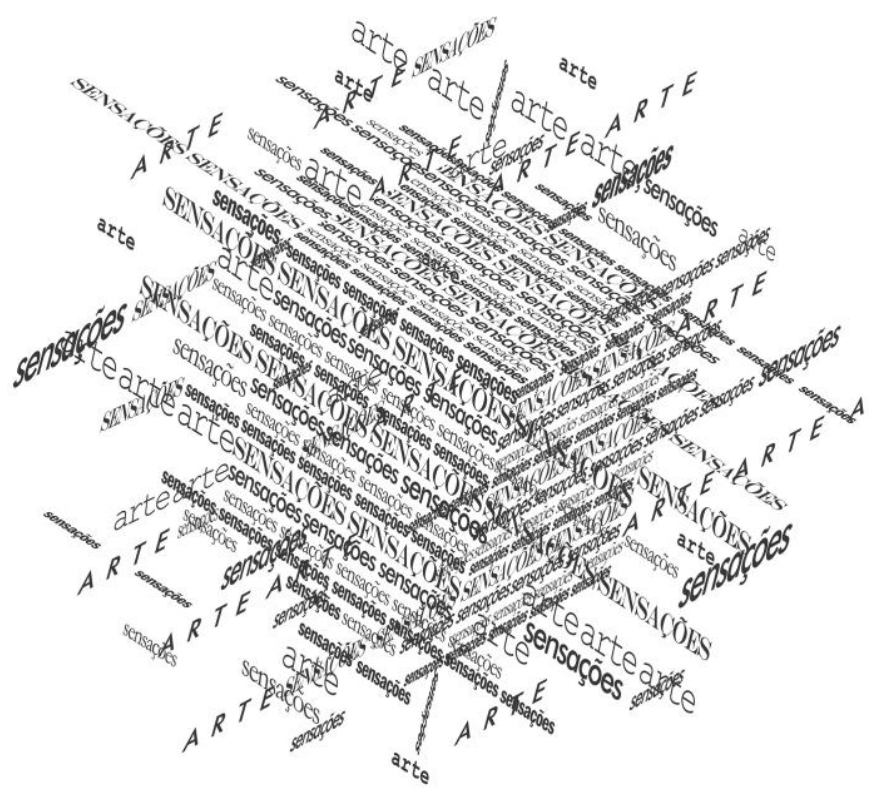

Bloco de Sensações (Riani Costa, 2016).

O propósito deste texto é apresentar-se como um jogo compositivo, em que estão dispostos alguns elementos: a infância, a linguagem, a imagem, a arte e a criança. Estes elementos estão presentes em 'Fragmentos'. O conjunto destes Fragmentos compõem o que estamos denominando de 'Faces'. O corpo do texto é composto de 6 faces, e estas compostas por 5 Fragmentos, formando, assim como na epígrafe acima, um bloco. A ideia é criar com estes elementos que estão dispostos de forma 'quase aleatória', um jogo onde possamos produzir e experimentar com as sensações, mas também experimentar as próprias sensações.

Este conjunto que chamaremos de Blocos de Sensações será a materialidade de possíveis encontros entre infância, educação e arte. Tal bloco será 'produto' de uma multiplicidade de possibilidades que aqui vão sendo constituídas a partir das experiências de bricolagem de cada leitor e esta será algo como aquilo que "se conserva, a coisa ou a obra de arte, é um bloco de sensações, isto é, um composto de perceptos e afectos" (DELEUZE, 2010, p. 93).

Essas composições, na perspectiva das conhecidas bricolagens, procuram criar campos abertos de possibilidades, são muitos modos de entrar neles e também são muitos os caminhos, com isso podemos depreender que, não obstante teremos muitas saídas. A perspectiva é que, ao criarem seus próprios percursos, os leitores apontem 'sendas' pouco pensadas, pouco ensaiadas, apresentam (nos próprios espaços vazios) ideias não ditas, não trabalhadas, não tratadas. O jogo se apresenta como exercício compositivo, o que 
dirige os propósitos desta 'brincadeira' são temáticas, argumentos, pensamentos, ideias acerca da educação e desta como uma experiência.

Este texto-jogo está composto de uma breve introdução, a qual chamaremos de "ensaios: começos (infâncias) de um movimento brincante", ao final desta introdução haverá uma proposição acerca do jogo. Após a introdução o texto está organizado em "6 Faces" e estas compostas de 5 fragmentos. As faces estão numeradas e nomeadas, e os fragmentos apenas numerados. O exercício é de compor 'livremente' com os fragmentos presentes nas faces. Em todas as faces um dos fragmentos é constituído de um espaço em branco, que objetiva exercer a função de um espaço para ideias, pensamentos, manifestações, imagens, do próprio leitor.

\section{Ensaios: começos (infâncias) de um movimento brincante}

Tomamos como ponto de partida o livro de Carlo Collodi "Pinóchio", bem como, nos pautaremos na versão para o cinema do filme, de Roberto Benigni de mesmo nome. Pinóchio, o menino-boneco, durante suas andanças por distintos territórios em seu percurso nômade, encontra Lucignolo, que se tornará seu mais terno e querido amigo e a quem ele carinhosamente chama de Espírito Nobre. Em outras versões desta história encontramos Lucignolo com o nome de Romeu - o peregrino, aquele que veio de Roma e também, algumas vezes Lucignolo aparece com o nome de Pavio, que significa pavio mesmo, que nos ditos populares muitas vezes nos referimos como "pavio curto", aquela pessoa impulsiva, pouco adepta a métodos mais racionais, seres assim um tanto parecidos com as crianças.

Lucignolo age como um daqueles que problematiza as práticas, os propósitos da escola. Ele, com frequência, olha para Pinóchio de maneira contundente, cria, com o olhar, uma atitude que insinua que jamais entregará seu corpo à práticas embrutecedoras, disciplinadoras e imperativamente diz: sou um espírito livre. O nobre amigo de Pinóchio o leva a bricolândia, a cidade dos brinquedos.

Na obra de Collodi e no filme Benigni, muito didaticamente, Lucignolo explica que na bricolândia o calendário obedece a uma outra perspectiva, cria e apresenta uma outra possibilidade, por lá, cada semana é composta de seis sextas-feiras e um domingo, anuncia ainda que as tão desejadas férias vão do primeiro dia de janeiro ao último dia de dezembro, ou seja, crava o anúncio de uma vida marcada por um outro tempo, ou mesmo poderíamos dizer, uma outra temporalidade, tudo isso faz prenunciar possibilidades de ocupação dos espaços, cria uma verdadeira ruptura com a rigidez de um tempo marcado por um calendário fixo, pré-determinado, ritmizado, ritualizado, é uma espécie de subversão presentes nestes outros espaços-tempos. 
O fato é que nada se alia tão bem ao ritmo de um calendário como a possibilidade de sua ritualização. Lévi-Strauss diz que os ritos fixam as etapas do tempo do calendário, como as localidades em um itinerário. Estas mobíliam a extensão, e aquelas, a duração. Ou seja, para Lévi-Strauss a função própria do ritual é preservar a continuidade do vivido (LEITE, 2012, p. 101).

As marcadas e rígidas estruturas dos calendários são violentamente destruídas de forma sutil pelo brinquedo e este, mesmo que não saibamos ainda como e por quê, altera o tempo, o destrói, o fato é que com seu didatismo, Lucígnolo nos ensina que brincando, o homem desprende-se do tempo sagrado e o 'esquece' no tempo humano, e com isso, e por oposição, temos que tempo e brinquedo se ligam intimamente nas atividades humanas.

É exatamente este ponto que nos interessa, pois visto desta forma, podemos compreender o brinquedo como um exercício de bricolar, ao brincar crianças e adultos lidam com fragmentos das coisas, velhas ou novas, retiram a parte de um todo, descontextualizam os objetos, rompem com os dogmas presentes em suas funções e significados, ao operarem com as partes, com os fragmentos, criam corpos, com as fissuras dos modos estruturais das coisas, criam adereços, produzem máscaras, distorcem os olhares.

Como um substantivo, o brinquedo subversivamente, assume o papel de verbo, cria em si mesmo a condição de ação e faz, assim como um cineasta quando edita seus filmes, quando um artista produz suas obras, ou seja, a partir de fragmentos de cenas, histórias e narrativas no brinquedo a criança entrecruza o tempo através dos "era uma vez", "um dia...", "você era...", você vai ser", e vai mapeando outras possibilidades, vai compondo com os cacos e com os fragmentos possibilidades para situações ainda não ditas, não pensadas, não vividas.

O brinquedo, em sua múltipla função de substantivo, sujeito e verbo, nos liga ao presente, ao passado e ao futuro, em uma dessacralização dos objetos. O brinquedo faz então o papel de transgredir o tempo, o espaço e os objetos, as narrativas, os sentidos, a linguagem. Junto a isso, ele também produz traços singulares, onde possíveis mundos são apresentados. É nessa perspectiva que propomos aqui um jogo, o qual se aproxima aos exercícios compositivos da 'técnica' Cut-up ${ }^{1}$, uma forma de brincar, de criar, de 'artistar' com algumas ideias, imagens, poesias, fragmentos.

A proposta é que cada leitor-escritor, artista-brincante, faça seus próprios movimentos, escolha uma das faces, em seguida escolha um dos blocos, a partir disso vá compondo seu próprio texto, seu próprio jogo compositivo.

\footnotetext{
1 Técnica de cortar e colar, jogo compositivo originário na literatura e incorporado por artistas plásticos de diferentes lugares do mundo.
} 


\section{FACE 1: Espaço-Tempo}

\section{Fragmento 1.1}

"Nos primeiros meses de 2003 era possível visitar, no Getty Museum de Los Angeles, Passions, exposição de vídeos de Bill Viola. Durante uma estada de estudos no Getty Research Institute, Viola trabalhara sobre o tema das expressões das paixões, que tinha sido codificado no século XVII por Charles Le Brun e retomado depois do século XIX, em bases científicos-experimentais, por Duchenne de Boulogne e por Darwin. O resultado desse período de estudo foram vídeos expostos na mostra. À primeira vista, as imagens sobre a tela pareciam imóveis, mas, depois de alguns segundos, elas começavam, quase imperceptivelmente, a se tornar animadas. 0 espectador percebia então que, na verdade, elas tinham estado o tempo todo em movimento e que somente a extrema lentidão, dilatando o movimento, as fazia parecer imóveis." (AGAMBEN, 2012, p.19).

\section{Fragmento 1.2}

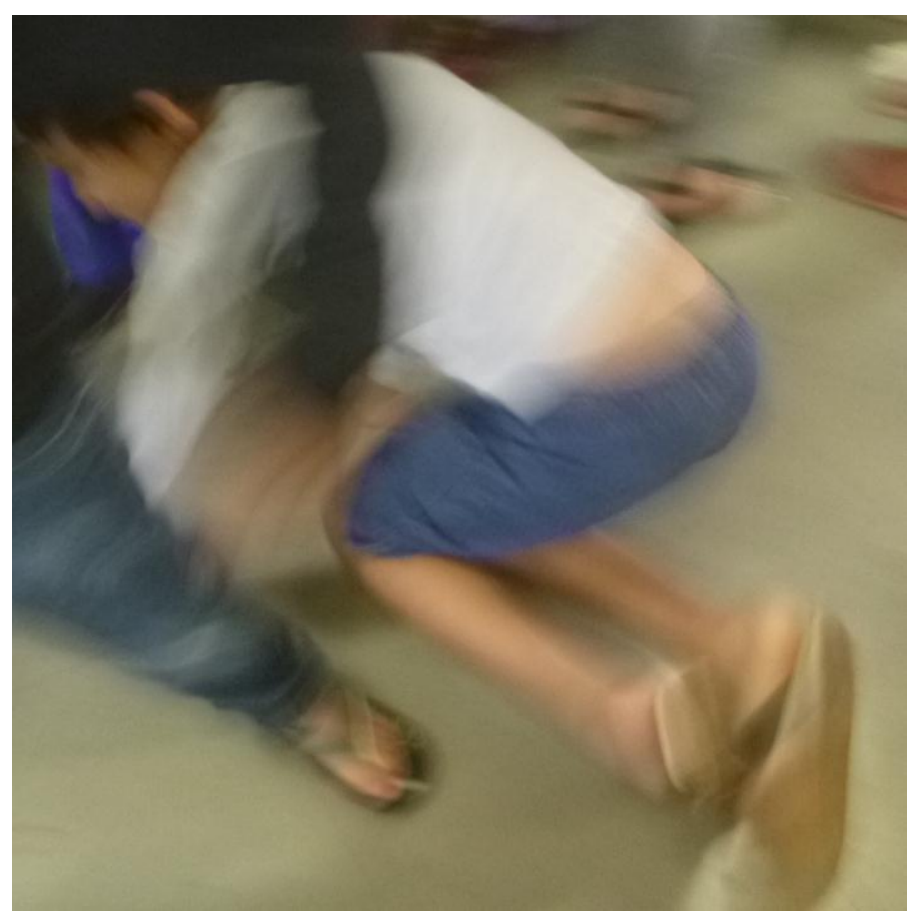

Figura 1: 'entre 1'

Fonte: elaborado pelo autor.

\section{Fragmento 1.3}

"Eu vi a manhã pousada em cima de uma pedra!

Isso não muda a feição da natureza?" (BARROS, 2010, p.459).

\section{Fragmento 1.4}

O que pode um texto, alterado pela arte, pela infância e pelas imagens produzir enquanto experiências de pensamentos? 
O que pode um texto que seja pré-texto, pretexto? O que pode um texto que se produz nos 'entre', nas entrelinhas, naquilo que não está nem em um lugar e nem no outro? O que pode um texto que, 'falando' sobre infância e arte, não se situe nem em um lugar e nem no outro? O que pode um texto que se faz e que se apresenta na fronteira? Fronteira, território de passagem, campo que liga um lugar ao outro, espaços de travessias.

\section{Fragmento 1.5}

\section{FACE 2: Corpos}

\section{Fragmento 2.1}

Enquanto o evento que eles apresentam pode durar até cerca de vinte minutos, esses vídeos exigem uma atenção à qual não estamos mais habituados. Se como Benjamin mostrou, a reprodução da obra de arte se contenta com um expectador distraído, os vídeos de viola obrigam, ao contrário a uma espera e a uma atenção - insolitamente longas (AGAMBEN, 2012, p. 20).

\section{Fragmento 2.2}

O homem de lata arboriza por dois buracos no rosto O homem de lata é armado de pregos e tem natureza de enguia O homem de lata está na boca de espera de enferrujar O homem de lata se relva nos cantos e morre de não ter um pássaro em seus joelhos

O homem de lata traz para a terra o que seu avô era de lagarto (BARROS, 2010 p. 127).

\section{Fragmento 2.3}




\section{Fragmento 2.4}

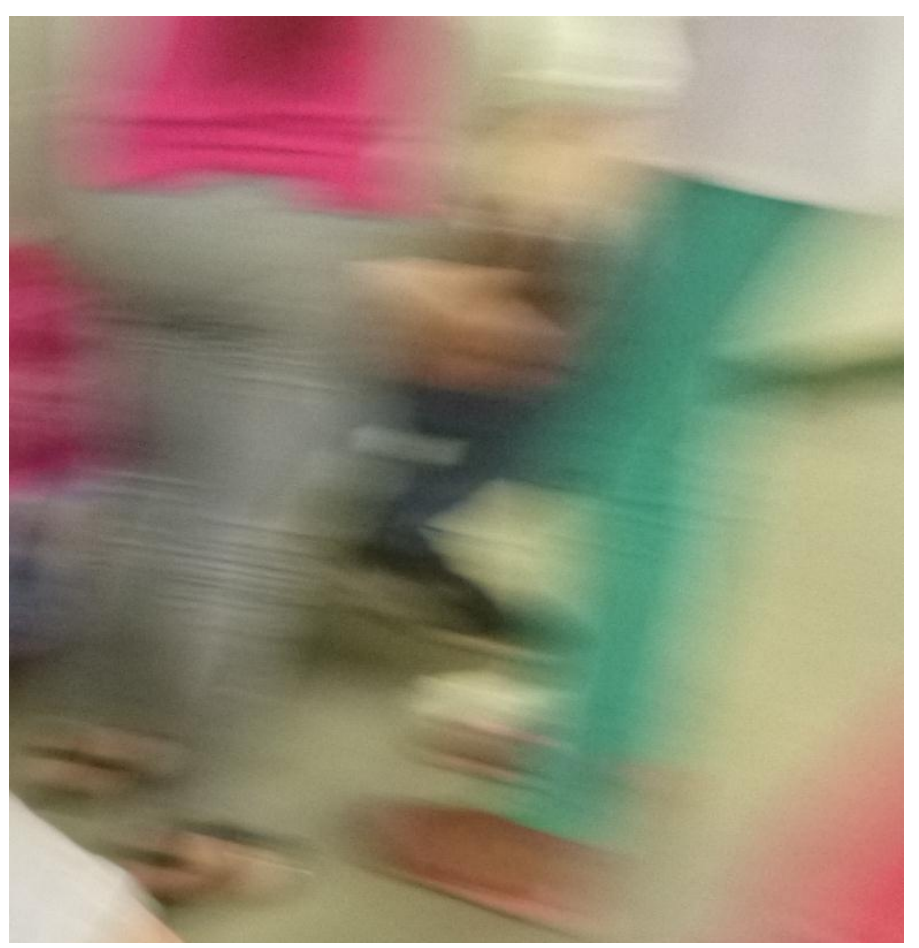

Figura 2: 'entre 2 '

Fonte: elaborado pelo autor.

\section{Fragmento $\mathbf{2 . 5}$}

Podemos pensar nas práticas educativas com as crianças de muitas maneiras. Diante dessa multiplicidade de modos, entre as várias facetas que se apresentam, a política é uma delas. Porém, também podemos afirmar que não há certos consensos ao conceituar e mesmo ao acenar algo acerca da política. Aqui, apontaremos que ao pensar em uma educação que seja permeada pela arte, por modos artistas e arteiros de ser educador.

A política se coloca para além do discurso e das práticas institucionais, a política ganha força e passa a ser pensada como a ação humana que produz mundos, mundos onde, através de agenciamentos e distante de uma perspectiva em que o ato político está longe de ser um elemento petrificado, a ação política se apresenta como uma espécie de "corpo sem órgãos ..., carne viva, que não se deixa totalizar em uma identidade estável, seja ela a massa, a classe, ou o povo" (BRASIL, 2008, p. 6).

Dessa forma, pensar a política na educação é uma ação que se desdobra em campos, os quais não se centram propriamente em uma ideia de sujeito, mas nos apresentam uma perspectiva que dialoga com traços de singularidade, de subjetividade. Nesse sentido, a subjetividade seria ponto de encontro, seria inventada, a partir de agenciamentos parciais e diagramáticos, onde se apresentam vários elementos constituintes do que chamamos de políticas, os elementos semióticos e artísticos. 


\section{FACE 3: Imagens-Movimento}

\section{Fragmento 3.1}

Como pode as imagens carregar-se de tempo? Que relação há entre imagens e o tempo? (AGAMBEN, 2012, p. 23).

Domenico chama de fantasma uma parada repentina entre dois movimentos, capaz de concentrar virtualmente na própria tensão interna a medida e a memória de toda a série coreográfica (AGAMBEN, 2012, p. 24).

\section{Fragmento 3.2}

Os amantes das rameiras são ágeis, felizes e devassos; quanto a mim, fraturei os braços.

Por ter me alçado além do chão.

(BENJAMIN, 1989 p. 79).

\section{Fragmento 3.3}

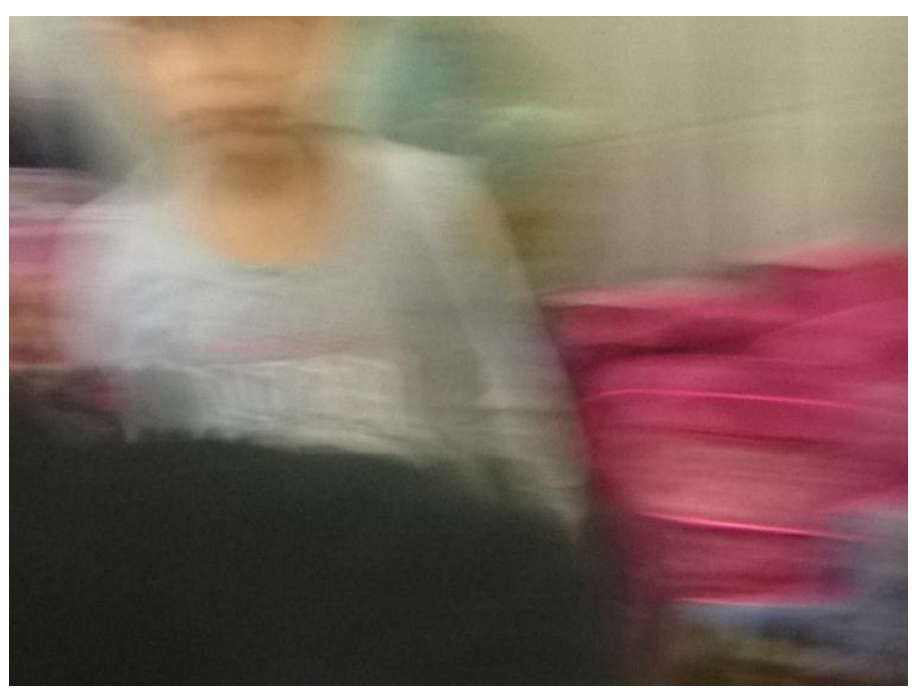

Figura 3: 'entre 3'

Fonte: elaborado pelo autor.

\section{Fragmento 3.4}

Em pesquisas de produção de imagens com crianças e professoras, que temos desenvolvido em Escolas Pública de Educação Infantil, temos observado que as imagens (fotos e filmes) produzidas pelas crianças são marcadas por cortes não propositais, mas acidentais, casuais, cortes não intencionais, que são produto de olhares rápidos, sem técnicas, olhares desfocados, repletos de perguntas, marcado por ruídos, definido por uma sonoplastia que nos deixa uma impactante sensação de abertura. 
Este estado infantil das imagens (e da própria pesquisa), cria, em nós, uma direção oposta à que usualmente está presente nas narrativas fílmicas e imagéticas de nossa cultura. Considerando o que frequentemente vemos, somos povoados por campo que anuncia neles próprios e nos deixa esperando saber o que vem depois; a infância pela criança apresenta-nos um mundo de reticências, um mundo pontilhado de possibilidades. Dito de outro modo, pesquisar com crianças e com infância, em nossos estudos, tem sido um contato com a abertura, o deslocamento em espaços e tempos.

O que observamos quando fazemos pesquisas com crianças e produção de imagens é um efetivo processo de exposição, de afetação, de experiência. São deslocamentos pelos quais enveredamos por travessias que escapam às certezas dos experimentos e dos protocolos de pesquisas, deslocamentos que nos permitem habitar outros tempos. Tempos distantes e fora das cronologias lineares de suscetibilidades de fatos e eventos, fora dos lugares e espaços seguros e previstos pela pesquisa.

Pesquisar com crianças é um convite a habitar a própria infância, infância da pesquisa, dos conceitos, dos mundos, do pesquisador. Pesquisar com crianças e produção de imagens tem sido, em certa medida, um puro desvio.

Nesses estudos, temos podido experimentar com as "infâncias" e, nessas experiências, destelhar territórios já definidos nos próprios campos conceituais, as crianças pelas imagens criam rupturas com lugares já dados, produzem outras espacialidades, como se as crianças estivessem distantes das amarras pré-definidas pelos currículos, pelas teorias de desenvolvimento que mexessem na tampa. Parece-nos que, com infâncias, podemos ser o outro dos espaços, podemos ser estrangeiros, ter sensações estrangeiras, ter na infância uma estrangeiridade com as coisas, ter uma estrangeiridade das coisas, se colocar na infância das coisas.

\section{Fragmento 3.5}

\section{FACE 4:}

\section{Fragmento 4.1}

Aqui, assim como no campo da arte, os modos de apresentação ganham algumas variantes, e as ideias acerca do que podemos qualificar como 'obra de arte' também. Neste campo, a dita linguagem artística pode ser representativa, apresentativa, produtiva, nestes casos, as imagens podem possuir semelhanças com os objetos, pode representar e ou mesmo retratar o mundo, podem apresentar aquilo que ainda não está ali, ou mesmo criar 
novos espaços, enfim, há uma multiplicidade de modos de falar das ditas linguagens artísticas.

O mesmo também, talvez possamos falar da infância e da criança. Mesmo que pesem as diferenças entre as noções de infância e de criança, escrever sobre ambas necessite, talvez, de estarmos submersos, estarmos em um campo de atividade com a criança, com a infância, implica uma forma de nos colocarmos nas infâncias das coisas e em nossa própria infância, exija um ato crianceiro, criancista, e o resultado talvez não seja outra coisa que esta possibilidade balbuciante, gaguejante de tropeçar nas palavras e nas ideias.

Quem sabe se o encontro da arte com a infância, da artistagem com a criança, exige de nós um texto que, em nossas próprias fissuras seja fragmento, seja uma escrita fragmentária, que contorne os pensamentos, que dê espaço para àquilo que está no campo visual e sensível e que também abra uma perspectiva para o que está no extracampo, ou seja, que está fora.

\section{Fragmento 4.2}

Olha o doce, nunca é o mesmo doce.

Todos os dias o doce é outro, porém mesmo.

O menino desejava aquele doce como se deseja um brinquedo, um carinho, um desejo.

Naquele dia, que ganharia o doce, passa do outro lado da rua um cachorro vira-lata, o menino então, dá as costas para a vitrine e corre atrás do doce vira-lata.

\section{Fragmento 4.3}

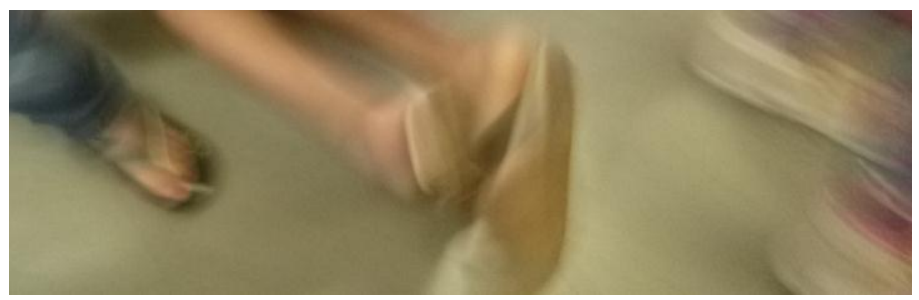

Figura 4: 'entre 4'

Fonte: elaborado pelo autor.

\section{Fragmento 4.3}

Nesse sentido, a imagem mnêmica está sempre carregada de uma energia capaz de mover e turbar o corpo: que a afecçãoo (pathôs) seja corpórea e a reminiscência uma busca nesse fanstasma, fica claro a partir do fato de que algumas pessoas ficam aflitas quando não conseguem lembrar-se de algo apesar da intensa aplicaçãoo da mente, e que a agitaçãoo perduratambém quando não está mais tentando lembrar - sobretudo os melancólicos, porque são muito mais abalados pelas imagens. O motivo pelo qual relembrarnão está 
sob o poder dessas pessoas é que, assim como aqueles que lançam um dardo não têm mais a possibilidade de detê-lo, aquele que procura algo na memória imprime certo movimento à parte corpórea na qual tal paixão reside.

A dança, portanto, é, para Domenichino, essencialmente uma operação conduzida sobre a memória, uma composição dos fantasmas (das imagens) em uma série temporalmente e especialmente ordenada. O verdadeiro lugar do dançarino não está no corpo e em seu movimento, mas na imagem como 'cabeça de medusa', como pausa não imóvel, mas carregada ao mesmo tempo, de memória e de energia dinâmica. Porém, isso significa que a essência da dança não é mais o movimento - é o tempo. (AGAMBEN, 2012, p. 25).

\section{Fragmento 4.5}

\section{FACE 5:}

\section{Fragmento 5.1}

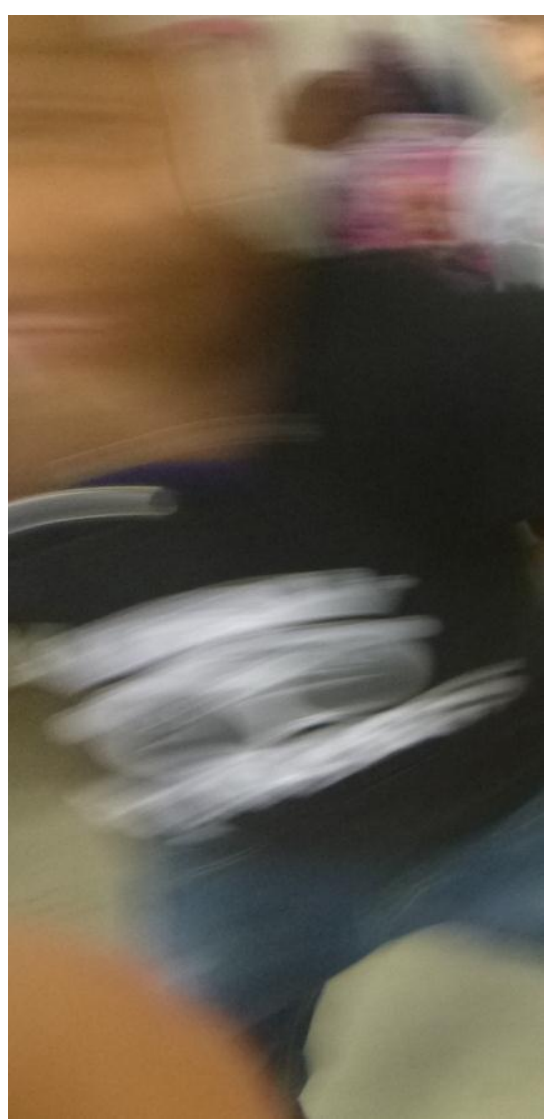

Figura 5: 'entre 5'

Fonte: elaborado pelo autor. 


\section{Fragmento 5.2}

Se no tranco do vento a lesma treme, No que sou da parede a mesma prega; Se no fundo da concha a lesma freme, Aos refolhos da carne ela se agrega; se nas abas da noite a lesma treva, no que em mim jaz de escuro ela se trava; se no seio da náusea a lesma gosma, no que sofro de musgo a cuja lasma; se no finco da folha a lesma escuma, nas calçadas do poema a vaca empluma! (BARROS, 2010, p. 219).

\section{Fragmento $\mathbf{5 . 3}$}

Na dinâmica dos trabalhos com as crianças, temos tentado fazer o esforço de não analisar, interpretar as imagens ou os processos de produção das crianças, mas, também para além de "pensar com as imagens", temos procurado fazer o movimento de "pensar por imagens". O fato é que as produções das imagens pelas crianças e as próprias imagens abrem uma perspectiva de olhar o corpo infantil que habita todo o processo de pesquisa, mas também cria em nós a necessidade de com o corpo. São corpos retorcidos para focar, para desfocar, corpos aproximados para ver os detalhes, detalhes que produzem sentidos, detalhes nunca vistos, nunca percebidos, detalhes de botões de camisas, de sujeira no nariz, de babas, detalhes de olhares rápidos.

As imagens nos provocam a pensar que educar o olhar não é propriamente oferecer técnicas, conhecimentos, teorias e sentidos, mas educar o olhar é como lançar o corpo em uma aventura, como ser colocado pelo corpo em um movimento de afetação, como se olhar não fosse um privilégio do olho, mas produto do corpo que experimenta com as 'imagenscâmeras' em 'cameraimagens'.

Tanto no processo da pesquisa como na relação com o pensar, a criança e a infância, este movimento nos retira dos lugares prévios de falar sobre infância e criança. As análises e interpretações demarcadas pelas descrições dos processos cognitivos e representativos sobre a criança e sobre as imagens, nos colocaram a levantar ao menos duas questões centrais: 1) indicada por uma perspectiva representacional no campo da linguagem imagética, que pretende sempre atribuir um sentido às imagens, por mais borradas e vertiginosas que sejam precisam dizer algo, precisam se encerrar em um sentido final, dito, dado, quase que 'revelando' verdades sobre as coisas, os objetos, as pessoas. Há uma concepção marcante de linguagem como representação e da imagem como uma linguagem representativa. 
Dessa forma, não fica difícil identificar que as imagens que "representam com mais nitidez", com mais clareza, são atribuídas às crianças que, segundo critérios das professoras, são mais desenvolvidas, espertas, inteligentes e que as imagens borradas, desfocadas, vertiginosas, são atribuídas às crianças que supostamente apresentam mais dificuldades. 2) Outro dado relevante que temos nos processos de produção: as crianças se misturam em corpos, misturam e cortam corpos, são corpos em movimentos, corpos em ação, corpos 'verbo'. É como se os corpos pensassem, como se pensasse pelo corpo, pensamentos sem sentidos, ameaçados por outros corpos, corpos invadindo e sendo invadidos, corpos mutilados, amputados de crianças que entregam as câmeras a outros colegas, o que vemos são movimentos disformes, corridas, círculos. Câmeras paradas, equipamentos sendo explorados, equipamentos explorados.

\section{Fragmento 5.4}

O espectador, a essa altura, se dá conta, com surpresa, de que a capturar sua atenção não há apenas animação de imagens que estava habituado a considerar imóveis. Trata-se mais de uma transformação que concerne à própria natureza dessas imagens. Quando, no final, o tema iconográfico foi recomposto, e as imagens parecem parar, elas estão, de fato, carregadas de tempo até quase explodir, e é justamente essa saturação cairológica que Ihes imprime uma espécie de tremor, que constitui sua aura particular. A cada instante, cada imagem antecipa virtualmente seu desenvolvimento futuro e lembra seus gestos precedentes. Se tivéssemos de definir em uma fórmula a contribuição específica de vídeos de Viola, poderíamos dizer que eles não inserem as imagens no tempo, mas o tempo nas imagens. Visto que, no moderno, não o movimento, mas o tempo é o verdadeiro paradigma da vida, isso significa que há uma vida das imagens que se deve compreender. Como o próprio autor afirma em uma entrevista publicada no catálogo: a essência da mídia visual é o tempo ... as imagens vivem dentro de nós ... nós somos databases viventes de imagens colecionadores de imagens - e já que as imagens estão dentro de nós, elas não cessam de transformar e crescer. (AGAMBEN, 2012, p. 21).

\section{Fragmento 5.5}


FACE 6:

\section{Fragmento 6.1}

Lembro só as coisas externas. Não é sossego dos serões de província que me enternece da infância que vivi neles, é a disposição da mesa para o chá, são os vultos dos móveis em torno da sala, são as caras e os gestos físicos das pessoas. É de quadros que tenho saudades. Por isso, tanto me enternece a minha infância como a de outrem: são ambas no passado, que não sei o que é, fenômenos puramente visuais, que sinto com a atenção literária. Enterneçome, sim, não é por que lembro, mas é por que vejo (PESSOA, 1982, p. 121).

\section{Fragmento 6.2}

No movimento dessas pesquisas com imagens e crianças na educação infantil, movimento demarcado por percursos mapeados por essas sinuosidades, vemos algo que, nas mesmas conexões daquilo que já apresentamos acima ganha um outro contorno, o 'tempo'. Como já descrito acima, nossos currículos, nossas práticas educativas, nossos modos de pensar e viver a educação estão pautados em um tempo processual, evolutivo, um tempo do progresso, um tempo cronológico, presente também em boa parte das teorias de desenvolvimento humano no campo da Psicologia, as ideias de fases, períodos, estágios, ou ainda a ideia de que evoluímos, tudo isso se organiza em uma esfera de uma modalidade de tempo.

O tempo cronos, cronológico e linear. As narrativas fílmicas, assim como as práticas escolares, na maioria das vezes, nos oferecem como enredos um olhar constituído por essa modalidade de tempo sequencial, lógico, cronológico. Porém, com as imagens produzidas pelas crianças nos vemos em outro deslocamento de tempo, uso aqui uma pequena passagem do texto "Ninfas" de Agamben, diz o seguinte, "a essência do meio visual é o tempo... as imagens vivem dentro de nós, somos colecionadores de imagens e uma vez que as imagens tenham entrado em nós não deixam de transformar-se e crescer", ou seja, dito de outro modo, não inscrevemos as imagens em um tempo, mas sim um tempo nas imagens. Quero dizer que as imagens curtas, rápidas, disformes, confusas, imagens paradas, imagens vultos, imagens fantasmas, todas elas apontam que outros tempos também que habitam o universo infantil. São imagens que pelo estranhamento (do não sentido, da não representação) que produzem criam uma sensação estrangeira com a infância, com a criança, criam uma estrangeiridade em nós e na criança. Na medida que 'inscrevemos um tempo nas imagens', podem nosso encontro com elas e com suas produções criar outras experiências com o tempo, com a educação? 


\section{Fragmento 6.3}

Sempre compreendo o que faço depois que já fiz.

O que sempre faço nem que seja uma aplicação de estudos. É sempre uma descoberta.

Não é nada procurado.

É achado mesmo (BARROS, 2010, p. 85).

\section{Fragmento 6.4}

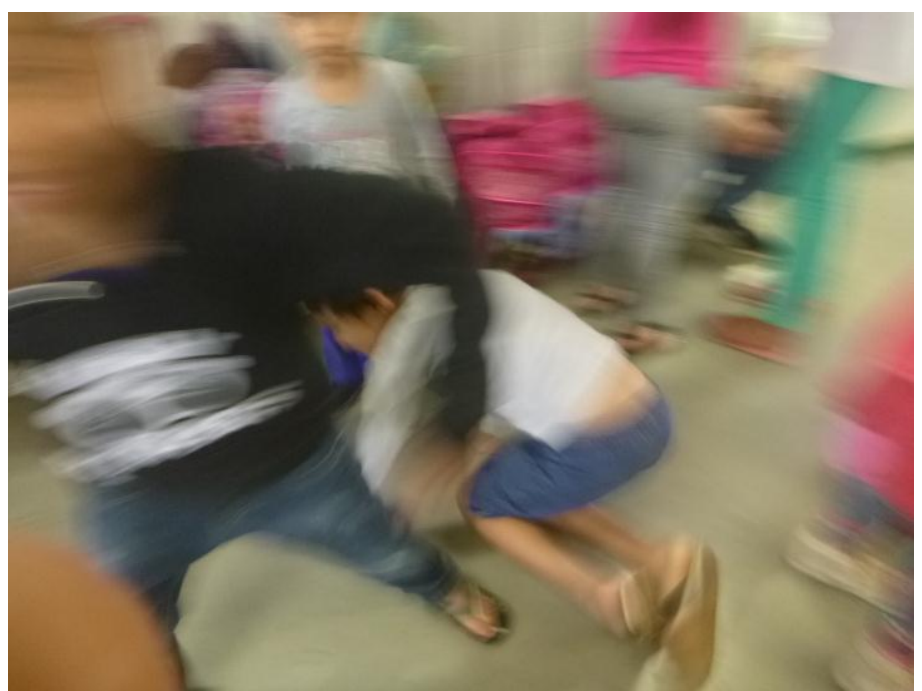

Figura 6: 'por entre'.

Fonte: elaborado pelo autor.

\section{Fragmento 6.5}

\section{Referências}

AGAMBEN, G. Infância e História: destruição da experiência e origem da história. Belo Horizonte, MG: Editora UFMG, 2005.

AGAMBEN, G. Ninfas. Valencia, Espanha: Pre-Texto, 2010.

BARROS, M. Poesia Completa. São Paulo, SP, Leya Editora, 2010.

BARROS, M. Memórias Inventadas. São Paulo: Editora Planeta, 2010.

BENJAMIN, W. Obras escolhidas II: rua de mão única. São Paulo: Brasiliense, 1995.

BRASIL, A. Modulação/Montagem: Ensaio sobre biopolítica experiência estética. Tese de 
Doutorado. Programa de Pós Graduação em Comunicação - Faculdade de Comunicação. Universidade Federal do Rio de Janeiro, 2008.

DELEUZE, G. O Que é a Filosofia? São Paulo: Editora 34, 2010.

LEITE, C. D. P. L. Infância, Experiência e Tempo. São Paulo: Editora Cultura Acadêmica, 2012.

PESSOA, F. Livro do Desassossego. São Paulo, SP, Editora Brasiliense, 1982.

RIANI COSTA, C. F. Caricatas: arte-rosto-humor-experiência. Tese de Doutorado. Rio Claro - SP: Universidade Estadual Paulista - UNESP, 2016.

' Possui graduação em Psicologia pela Pontifícia Universidade Católica de Campinas (1991). Mestrado (1996) e doutorado (2002) em Educação pela Universidade Estadual de Campinas - UNICAMP. Pós-Doutorado pela FLACSO Argentina em 2008 e pela Universidade Complutense de Madrid 2012. Livre Docência pela UNESP em 2011. Atualmente é Professor Adjunto da Universidade Estadual Paulista - UNESP Rio Claro e foi Professor Visitante na Universidade Católica de Leuven - Bélgica em 2011.

Como citar esse artigo:

LEITE, César Donizetti. Blocos, infância e crianças: entre movimentos e ensaios brincantes.

Revista Digital do LAV, Santa Maria: UFSM, v. 14, n. 2, p. 321-336, mai./ago. 2021. 